\title{
Biomass conversion into valuable products within the integrated management of bio-resources
}

\author{
Gabriela Ionescu, ${ }^{1, *}$, and Cora Bulmău ${ }^{1}$ \\ ${ }^{1}$ University Politehnica of Bucharest, Department of Energy Production and Use, Splaiul Independenţei 313, Romania
}

\begin{abstract}
The present research proposes two scenarios for the biomass conversion into valuable products within the integrated management of bio-resources. The scenarios have been developed considering: the biomass availability, material and by-products characteristics and the comprehensive combination of the primary technologies used for the conversion of the biomass mixtures into energy. In scenario 1 the biomass waste valorisation is made via integrated pyrolysis and combustion treatment, while in scenario 2 the biomass conversion in done considering the integration of the pyrolysis, gasification and combustion treatments into the conversion chain. The results revealed that all analysed scenarios purposed are selfindependent from the energetic point of view.
\end{abstract}

\section{Introduction}

Waste to energy has become an attractive approach due to the effective partial or total replacement of common fossil fuels. In this context, biomass waste represents one of the primary candidates, being one of the oldest renewable energy sources, available in abundance, with a relatively unitary structure. The energy derived from biomass or bioenergy represents the most versitale renewable energy source. In comparison with others viable resources, biomass can be converted into solid, liquid and gaseous fuels. Its carbon neutral nature could contribute to the achievment of the greenhouse gas emission reduction by 2050 with $50-80 \%[1]$. The European Union already started its transition towards a bio-based economy that implies a legislative, tehnical, enviromental and economical sustainable mobilization on the biofuels and bioenergy production and usage [2].

The statistics regarding the estimation of bioenergy potential are slightly different when it comes to its spatial and temporal scale assessment. According to the data provided by accreditate monitors such Eurostat and Worlbioenergy presented in Fig. 1., the foresty residues represent the most predominant biomass resource worlwide, while the forestry and crops residues seems to be the primary biomass sources in the European region, followed by agricultural waste in both cases $[3,4]$.

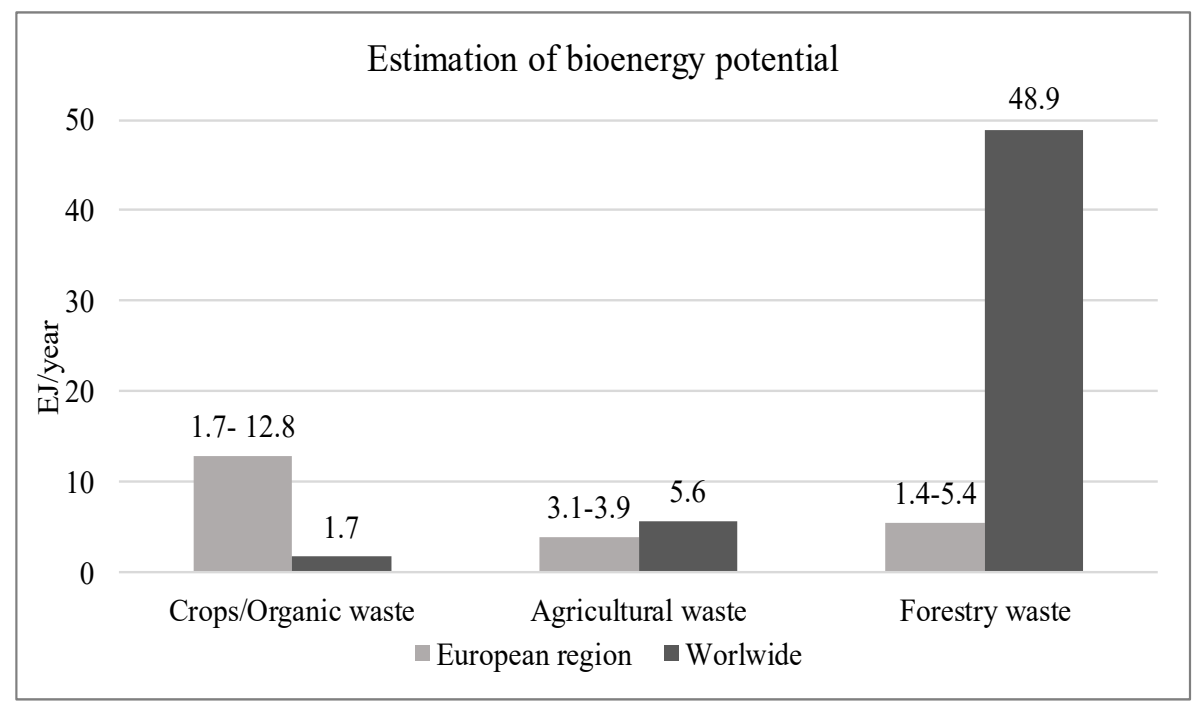

Fig. 1. Estimation of bioenergy potential.

\footnotetext{
* Corresponding author: gabriela_ionescu@ymail.com
} 
A considerable amount of studies have been published on woody, non-woody and agricultural waste conversion treatments that included: pyrolysis [5], gasification [6], combustion/co-combustion [7,8], bio-oil upgrade [9], transesterification [10], biological treatment [11]. Others concentrated on the biomass logistics and/or supply chain optimization[12].

After a brief analysis of the mentioned studies, the amount and quality of the resulted bioenergy/fuel, along with their distribution is mainly given by: the physical and chemical caracterictics of the biomass, type of conversion treatment, design amd operation process parameters (e.g. residence time phase, temperature, pressure, type of agent) and the recovery/ valorization unit. Overmore, it seems that the scale-up of an integrated biomass/waste to energy system with industrial implementation still represents an ongoing challenge $[13,14]$. The planning scheme of the bioenergy/fuel production systems should consider several important tehnical pillons:

a) logistics upstream of the treatment - operations that involve harvesting and collection, storage, pre-treatment and transportat;

b) suitable conversion technologies and processes;

c) logistics downstream of the treatment: storage, transportation and an open market for the bioenergy/biofuels distribution.

The wide knowledge of the authors, in these fields, gain thourgh experimental approaches and permanet contact with the industrial stakeholders has led to the developement of the present study. The current paper proposes, two scenarios for the biomass conversion into valuable products within the integrated management of bio-resources.

\section{Material and methods}

The primary characteristics of any type of fuel and its availabilty represent the starting point of an energetic scheme concept. For the development of the research typically woody and non-woody biomass properties were considered. The ultimate and proximate analysis and heating value of the typically biomass characteristic are presented in table 1 .

Table 1. Typically, biomass chemical properties [15-19].

\begin{tabular}{|l|l|l|}
\hline \multicolumn{1}{|c|}{ Biomass } & Unit & $\begin{array}{c}\text { Biomass } \\
\text { characteristic. } \\
\text { Average values }\end{array}$ \\
\hline Ultimate analysis & \multicolumn{2}{c|}{} \\
\hline $\mathrm{C}$ & \%d.a.f. & 44.9 \\
\hline $\mathrm{H}$ & \%d.a.f. & 5.8 \\
\hline $\mathrm{O}^{*}$ & \%d.a.f. & 40.7 \\
\hline $\mathrm{N}$ & \%d.a.f. & 1.0 \\
\hline $\mathrm{S}$ & \%d.a.f. & 0.1 \\
\hline $\mathrm{Cl}$ & \%d.a.f. & $<0.02$ \\
\hline Proximate analysis & & \multicolumn{2}{|l}{} \\
\hline Moisture & \%a.r. & 5.6 \\
\hline VM & \%a.r. & 75.6 \\
\hline A & \%a.r. & 9.1 \\
\hline FC* & \%a.r. & 19.9 \\
\hline High Heating Value & MJ/kg & 18.33 \\
\hline
\end{tabular}

where:

$-\mathrm{C}, \mathrm{H}, \mathrm{O}, \mathrm{N}, \mathrm{S}, \mathrm{Cl}$ are the main chemical elementscarbon, hydrogen, oxygen, nitrogen, sulfur and chlorine expressed in percentage dry ash free (\% d.a.f)

- VM, A, FC are the Volatile Matter, Ash and Fix Carbon content expressed in percentage as received (\% a.r.)

-* the Oxygen and Fixed Carbon were calculated by difference.

The design of the integrated biomass pyrolysis and by-products usage relias on the following treatments:

- Shredding is the main pre-treatment used before any type of biomass waste processing. The particle size dimension is imposed by the type of reactor used that that can reach to an average value of $53 \mathrm{~mm}$ [20]. The specific cutting energy is typically $20.1 \mathrm{kWh} /$ ton [21].

- Mixers/ /homogenizer offers a homogeneous input stream that is mainly define by the: particle size distribution, mean-density and size ratio, average moisture and bulk properties. The average energy consumption for the mixing process is $0.893 \mathrm{kWh} / \mathrm{ton}$ [22].

-Feeding system transports the biomass waste into the pyrolysis reactor through a conveyor belt coupled with an auger/screw system. The role of the feeding chain is to ensure a constant fuel input across the grate. The average consumption of the system is $0.72 \mathrm{kWh} /$ ton of waste [23].

-Pyrolysis is the thermal cracking of a substance into smaller fragments in the absence of oxygen. In comparison with other thermo-chemical treatments (e.g. combustion and gasification) through the pyrolysis biomass, three types of energetic by-products can be produced: biofuel, biochar and pyrolysis gas. It seems that the optimal operating pyrolysis process temperature for bio-oil production from most types of biomass varies between $500-600^{\circ} \mathrm{C}[5]$.

Depending on the heating rate and final temperature, the process is classified as slow, intermediate or flash pyrolysis, where the by-products distribution can vary between $13-35 \%$ for pyrolysis gas, $30-80 \%$ for bio-oil, and $2-35 \%$ for biochar [ 24-25].

The main pyrolysis gaseous components are carbon dioxide $\left(\mathrm{CO}_{2}\right)$ carbon monoxide $(\mathrm{CO})$, methane $\left(\mathrm{CH}_{4}\right)$, hydrogen $\left(\mathrm{H}_{2}\right)$, small number of non-methane hydrocarbons (ethane $\left(\mathrm{C}_{2} \mathrm{H}_{6}\right)$, and ethene $\left(\mathrm{C}_{2} \mathrm{H}_{4}\right)$, propane $\left(\mathrm{C}_{3} \mathrm{H}_{8}\right)$ ), traces of nitrogen oxides (NOx), sulfur oxides $\left(\mathrm{SO}_{\mathrm{x}}\right)$, ammonia $\left(\mathrm{NH}_{3}\right)$, and alcohols with a low carbon number. It is worth mentioning that the increasing of heating rate favours the evolution of $\mathrm{H}_{2}$, while hydrocarbon species and $\mathrm{CO}$ concentrations decrease. Generally, the average lower heating value (LHV) of the pyrolysis gas resulted from lignocellulosic fuels is $15 \mathrm{MJ} / \mathrm{m}^{3}{ }_{\mathrm{N}}$ [26].

The energy potential of the bio-oil resulting from the biomass pyrolysis process is strongly influenced by the moisture content and high degree of oxygen present in the material. Among the resulting liquid products, methanol is one of the most valuable products. The major constituents of bio-oil are the phenolic compounds as well as their alkylated, polyphenolic derivatives, and relatively small amounts of phenol, eugenol, crezoles 
and xylenols [27] The higher heating value (HHV) of the bio-oil produced from biomass waste reaches to an average value of $17.9 \mathrm{MJ} / \mathrm{kg}$, closely to ethanol, being almost 2.5 times lower in comparison with petroleum oils ( $\approx 43.5 \mathrm{MJ} / \mathrm{kg})$ [28].

The average HHV of biochar resulted from the biomass pyrolysis process approximately $28 \mathrm{MJ} / \mathrm{kg}$ [29], making it a reliable candidate for fossil substituent such as: anthracite, semi- anthracite, bituminous coal, subbituminous coal and coke. Biochar can be also used as soil amendment and carbon capture agent.

Gasification is the thermochemical process which happens in the presence of a partial oxidant atmosphere that converts carbonaceous resources into syngas, tar and char/ash. The syngas or synthesis gas produced from biomass is mainly composed by $\mathrm{CO}, \mathrm{CO}_{2}, \mathrm{H}_{2}, \mathrm{CH}_{4}$, water vapours and light hydrocarbons, additionally $\mathrm{N}_{2}$ if air is used as gasifying agent. Depending on the gasifying agent, (air, steam, oxygen, $\mathrm{CO}_{2}$ or steam and oxigen) the average LHV of syngas from biomass is round $16 \mathrm{MJ} / \mathrm{m}^{3}$, allowing its usage in a large variety of energetic applications [6]. In comparison with pyrolysis process, the gasification is considered the most efficient environmentally friendly route of biomass conversion into gas-based energy, reaching up to conversion efficiencies higher than $50 \%$ [30]. The char produced from the lignocellulosic based material can be used as activated carbon.

Combustion of the biomass represents a relatively mature technology, that aims to fully burn the feedstock towards direct power and heat generation. Today, the biomass combustion is typically made in fluidized bed reactors at temperatures ranging between $800-900{ }^{\circ} \mathrm{C}$. The main technological challenges of the biomass combustion are: presence of non-combustible contaminants, moisture content (if the long term storage isn't appropriate made), pre-treatment and preprocessing stages, adequate transport and rich content of mineral matter and alkaline earth metals (e.g. potassium and calcium) that during the combustion process might lead to the slagging, fouling, agglomeration and corrosion of the reactor [31].

\section{Results and discussion}

Two scenarios (Scenario 1. and Scenario 2.) have been developed for energy and secondary material production from the waste biomass mixtures. The scenarios have been design based on: the biomass availability, material and by-products characteristics and the comprehensive combination of the primary technologies used for the conversion of the biomass mixtures into energy. Figure 2 (Scenario 1.) and Figure 3 (Scenario 2.) present the proposed integrated biomass waste conversion chains into energy and valuable products. The mass and energy balance are expressed in percentage. The common points of the developed scenarios (Figure 2 and Figure 3 ) are:

- The biomass input flow is given by a mixture of crops, forestry and agricultural waste. The choice of the biomass mixture was made based on the disposability of these kind of waste at global level, making it handy to use.

- After harvesting and collection, the biomass residues are deposited in controlled storages systems in order to avoid the degradation of the feedstock, its premature decomposition, moisture gain or spontaneous combustion. During these procedures $2 \%$ from the initial feedstock mass is lost, while another $2 \%$ is energetically consumed.

- The pre-processing stage includes two steps: 1. Shredding and 2. Homogenization of the waste. The preMJ/kg [33], ma processing chain represents a crucial point for the biomass waste further usage in any kind of treatment. From the initial feedstock input flow, the average mass percentage loss during the biomass shredding process reaches out to $4 \%$, while the energy consumption to $4.4 \%$. To those are added another $1.5 \%$ mass and $0.1 \%$ energy loss, absorbed by the mixer/ homogenizer.

- The homogenized biomass is sent to a thermaltreatment in non-oxidant atmosphere (pyrolysis). The thermal energy consumption of the pyrolysis process is given through the combustion of a certain quota of pyrolysis products. The energy balance of the process used in our computation is given below:

$$
Q_{i}+Q_{p}=Q_{\text {char }}+Q_{\text {tar }}+Q_{\text {gas }}+\Delta Q
$$

where:

$Q_{i}$ is the input energy provided by the biomass; $Q_{p}$ is the process heat comsuption; $Q_{\text {char }}, Q_{t a r}, Q_{\text {gas }}$ are the pyrolysis products energy content; $\Delta Q$ is the by-products sensitive heat and pyrolysis reactor heat losses.

- In comparison with other thermal-treatments that require the presence of oxidant agent, the biomass pyrolysis process enhances the production of bio-fuel oil type. In this case the average production is approximately $53 \%$ from the pyrolyzed feedstock input mass, with an average energy content of $67.1 \%$. However, the considerable water content and viscosity, low $\mathrm{pH}$, etc. doesn't make it suitable for direct usage as a fuel in diesel engines. In this case an upgrading of the bio-oil is necessary.

- The upgrading of the bio-oil will impoverish the conversion system with an additional mass loss of $25 \%$, and $17.6 \%$ energy respectively.

- As the results show that the biofuel produced represents $35 \%$ in average from the initial feedstock input. It seems that overall biodiesel represents the most up trended bio-resource, that can improve the oxidation stability during its usage in the engine, and therefore emission reduction.

- In average the gas produced represents $26 \%$ from the pyrolyzed feedstock. Its considerable rich composition in $\mathrm{CO}_{2}, \mathrm{CO}, \mathrm{CH}_{4}$ and $\mathrm{H}_{2}$ make it suitable for its thermal treatment in oxidant based atmosphere.

- In average the biochar produced represents $21 \%$ from the pyrolyzed feedstock. Due to its valuable properties it can be used as material in agricultural or industrial purpose or energetically recovered. 
The distinction between the two scenarios are given by the recovery of the pyrolysis gas and biochar byproducts as follows:

- In Scenario 1. the pyrolysis gas and biochar are sent to a co-combustion chamber. Part of the energy produced is used in the pyrolysis process $(43.2 \%)$, while the rest $(25 \%)$ in thermal energy systems. In this case the biomass waste conversion via integrated pyrolysis and combustion treatment can be considered as an independent free energy system. The 5\% ash resulted from process the can be used as supplement in batching plants, road construction, building material, etc., or if not either the case it can be sent to a sanitary landfill.

- In Scenario 2. the pyrolysis gas still represents the primary fuel support for the pyrolysis process. In comparison with Scenario 1. due the biochar absence, as supplement in the combustion process, the energy used in the pyrolysis system is reduced with $15 \%$. As presented in Fig. 3 (Scenario 2) the 20\% in mass of biochar can be:

Option A: Soil amendment. The use of biochar to improve the soil quality represents an efficient method because it helps the retention in soil of nutrients and agrochemicals, compounds that are very important for the plant development and crop utilization [32]. It is recognized that biochar naturally contains many of the micronutrients required by plants and improves the soil texture and ecology, increasing its capacity to retain fertilizers and release them slowly.

Option B: Activated carbon. The biochar produce can be used as activated carbon for water purification, heavy metal treatment, removal of organic pollutant or contaminated soil remediation.
Option C: Gasification.

To maximize the overall biomass to energy conversion the gasification process was used for char to syngas conversion as a complementary process to bio-oil production. The energy efficiency of the process as well as the heat consumption was determined by using the following equations:

$$
\mathrm{CGE}=\frac{\mathrm{LHV}_{\text {gas }} * \mathrm{M}_{\text {gas }}}{\mathrm{LHV}_{\text {biomass waste }} * \mathrm{M}_{\text {biomass waste }}}
$$

$$
\mathrm{HGE}=\frac{\mathrm{LHV}_{\text {gas }} * \mathrm{M}_{\text {gas }}+\mathrm{M}_{\text {gas }} * \mathrm{c}_{\mathrm{pgas}} *\left(\mathrm{~T}_{\text {gas }}-\mathrm{T}_{\text {biomass waste }}\right)}{\mathrm{LHV}_{\text {biomass waste }} * \mathrm{M}_{\text {biomass waste }}}
$$

where:

- $\quad \mathrm{c}_{\mathrm{pga}}$ is the gas specific heat $\left[\mathrm{J} / \mathrm{kg}^{*} \mathrm{~K}\right]$

- $\quad \mathrm{T}_{\text {gas }}$ is the temperature of the syngas output $[\mathrm{K}]$

- $T_{\text {biomass waste is the temperature of the feedstock }}$ (biomass waste) input gasification reactor

- $\quad$ LHV is the Lower Heating Value $[\mathrm{kJ} / \mathrm{kg}]$

- $\quad \mathrm{M}$ is the biomass mass [kg]

The biochar gasification enhances the production of gas fuel (syngas), reaching out to total mass of $30 \%$. An additional $40 \%$ of the initial energy is consumed during the gasification process. The syngas be used for electricity and heat generation (in combustion engines or gas turbines) or in chemical industry, synthesize fertilizers and liquid fuels. As stated above the 5\% ash content resulted from the gasification process has a wide range of industrial applications if meets several standard requirements.

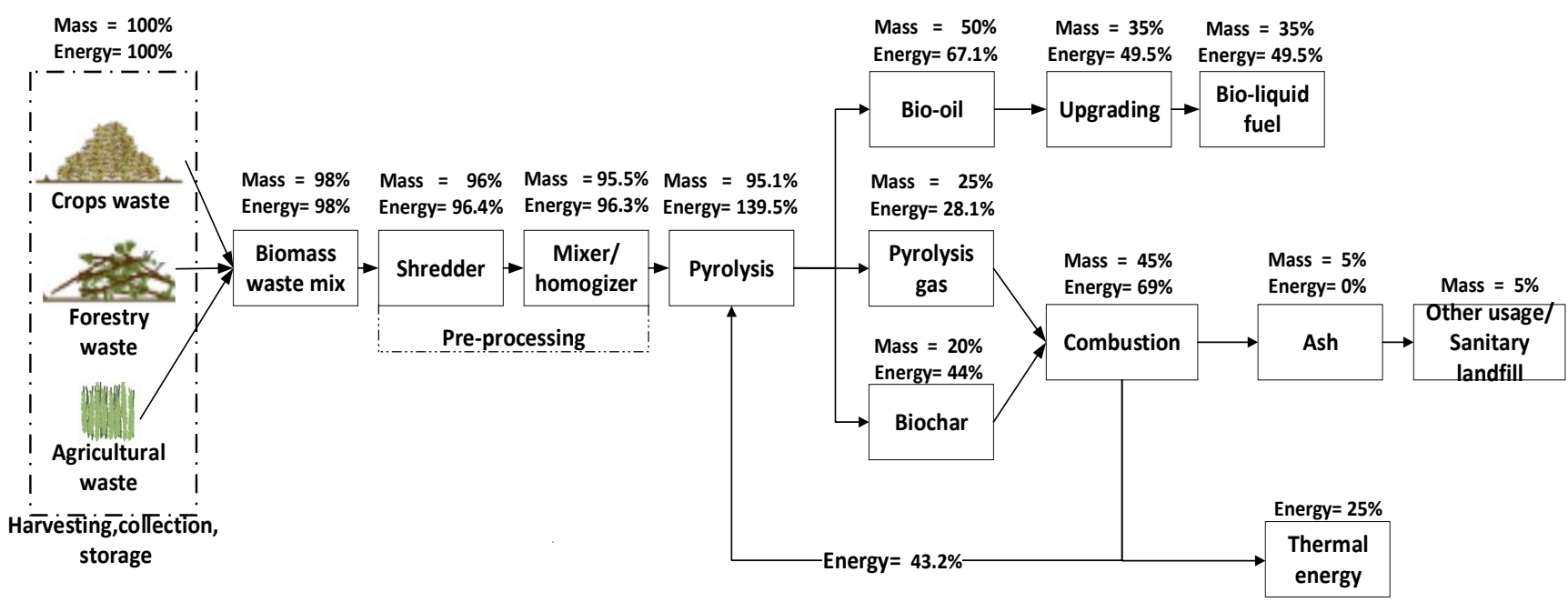

Fig. 2. Scenario 1: Biomass waste conversion via integrated pyrolysis and combustion treatment. 


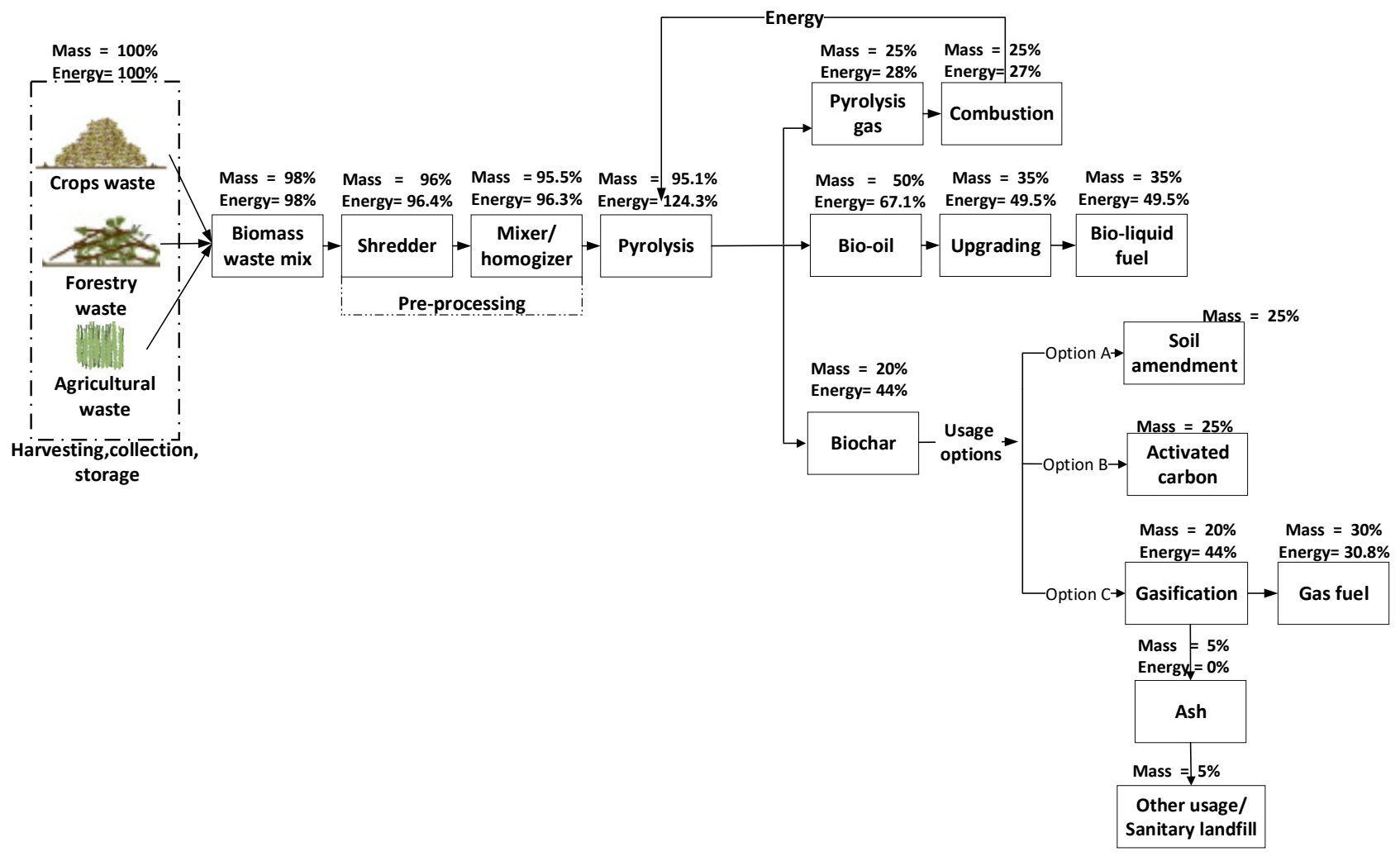

Fig. 3. Scenario 2: Biomass waste conversion via integrated pyrolysis, gasification and combustion treatments.

\section{Conclusions}

As overall conclusion, the comprehensive combination of different technologies (including pre-processing stage, energy production and usage of the by-products) offer a reliable insight on the biomass conversion into valuable products within the integrated management of bioresources. The pre-processing stage represents an essential preliminary step that offers a homogeneous feedstock input that follows the pyrolysis reactors specification. In comparison with gasification or combustion processes the pyrolysis process enhances the production of bio-oil.

In both cases the bio-oil production from the total pyrolyzed biomass mixture is approximately $53 \%$.

The first scenario (Scenario 1) integrates the usage of the pyrolysis gas and biochar in a combustion system. It is estimated that $43.2 \%$ of the energy produced during the combustion process can be used in the pyrolysis system, while the other remaining $25 \%$ for external thermal energy usage.

The second scenario (Scenario 2) integrates the pyrolysis gas valorisation in a combustion chamber. The energy resulted is used in the biomass pyrolysis process. As resulted, due to the biochar absence in the cocombustion process the energy recovered is with 2.5 times lower in comparison with the first scenario. As previews discussed the biochar produced can be used as soil amendment or activated carbon or as primary fuel in a gasification process.
Acknowledgements: Funding provided through Romania's "Competitiveness Operational Programme 2014-2020", Priority Axis 1: Research, Technological Development and Innovation (RD\&I) to Support Economic Competitiveness and Business Development, Action 1.1.4. Attracting high-level personnel from abroad in order to enhance the RD capacity. ID/Cod My SMIS: P_37_768/103651;No.Contract: 39/02.09.2 016.

\section{References}

1. J. Bogner, R. Pipatti, S. Hashimoto, C. Diaz, K. Mareckova, L. Diaz, P. Kjeldsen, S. Monni, A. Faaij, Q. Gao, Waste Manag. Res., 26, pp. 1132, (2008)

2. E. C. Rada, M. Ragazzi, V. Torretta, G. Castagna, L. Adami, L. I. Cioca, AIP Conference Proceedings, AIP Publishing 1968, p. 030050, (2018)

3. H. Long, X. Li, H. Wang, J. Jia. Renew. Sust. Energ. Rev., 26, 344-352, 2013

4. Report on Global biomass potential towards 2035 , website:

https://worldbioenergy.org/uploads/Factsheet_Biom ass\%20potential.pdf, Last access July 2018

5. V. Dhyani, T. Bhaskar, Renew. Energ., 129, 695716, (2018).

6. S. Ciuta, D. Tsiamis, M. J. Castaldi, Academic Press, (2017).

7. J. D. D- Morris, S. S. Daood, , S. Chilton, W. Nimmo. Mechanisms and mitigation of 
agglomeration during fluidized bed combustion of biomass: A review. Fuel, 230, 452-473, (2018)

8. S. G. Sahu, N. Chakraborty, P. Sarkar (2014). Coal-biomass co-combustion: An overview. Renewable and Sustainable Energy Reviews, 39, 575-586.

9. H. A. E-Baloch, S.Nizamuddin, M. T. H. Siddiqui, S. Riaz, A. S Jatoi, D. K Dumbre, G. J. Griffin, J. Environ. Chem. Eng. , 6, 5101-5118, (2018).

10. M. Barekati-Goudarzi, D. Boldor, D. B. Nde. Bioresource Technol., 201, 97-104, (2016).

11. G. Andreottola, M. Ragazzi, P. Foladori, R. Villa, M. Langone, Rada, E. C. University" Politehnica" of Bucharest Scientific Bulletin, Series C: Electrical Engineering, 74(1), 19-26, (2012).

12. K. T. Malladi, T. Sowlati. Renew. Sust. Energ. Rev., 94, 587-599, (2018).

13. E. Ranieri, G. Ionescu, A. Fedele, E. Palmieri, A. C. Ranieri, V. Campanaro. Waste Manage Res, 35(8), 890-898, (2017).

14. G. N. Sava, G. Ionescu, H. Necula, M. Scripcariu, M. Q. Duong, S. Leva, M. Mussetta (EEEIC/I\&CPS Europe), 2017 IEEE International Conference on (pp. 1-5). IEEE (2017).

15. R. N. Tirtea, I. Stanciulescu, G. Ionescu, , C. Bulmau, C. Marculescu, D Boldor. CIEM 2017 International Conference, 390-393). 2017, October.

16. S. Sadaka, H. Liechty, M. Pelkki, M. Blazier. Bio. Resources, 10(3), 4498-4518, (2015).

17. B. Zhang, Z. Zhong, M. Min, K. Ding, Q. Xie, R. Ruan, Bioresource Technol., 189, 30-35, (2015).

18. J. Makibar, A. R. Fernandez-Akarregi, M. Amutio, G. Lopez, M. Olazar. Fuel Process Technol., 137, 283-289, (2015).

19. J. Park, Y. Lee, C. Ryu,Y. K. Park. Bioresource Technol., 155, 63-70, (2014).

20. L. J. Naimi, S. Sokhansanj, S. Mani, M. Hoque, T. Bi, A. R. Womac, S. Narayan. 2006 ASAE Annual Meeting (p. 1). American Society of Agricultural and Biological Engineers], (2006).

21. A. Kronbergs, E. Kronbergs, E. Repsa, M. Smits. Bale shredder efficiency dependence on settings. 12th International Scientific Conference: Engineering for rural development, (pp. 477-481). (2013).

22. A. K. Lee, D. M. Lewis, P.J. Ashman. Chem. Eng. Res. Des., 88(8), 988-996, (2010).

23. J. Frey, F. Grüssing, H. J. Nägele, H. Oechsner. Landtechnik, 68(1), 58-63, (2013).

24. L. Zhang, R. Liu, R. Yin, Y. Mei, Renew. Sust. Energ. Rev., 24, 66-72, (2013).

25. Q. Lu, W. Z. Li, X. F. Zhu. Energ. Convers. Manage., 50(5), 1376-1383, (2009).

26. V. Karkania, E. Fanara, A. Zabanioto. Renew. Sust. Energ. Rev, 16(3), 1426-1436, (2012).
27. R. H. Venderbosch., W. Prins Biofuel Bioprod. Bior., 4.2 ,178-208, (2010).

28. A. Demirbas. Fuel Process Technol., 88(6),591597,(2017).

29. M. Ahmad, A. U. Rajapaksha, J. E. Lim, M. Zhang, N. Bolan, D. Mohan,\&.. Y. S. Ok, Chemosphere, 99, 19-33, (2014).

30. C. A. Alzate, F. Chejne, C. F. Valdés, A. Berrio, J. De La Cruz, \& C. A. Londoño, Fuel, 88(3), 437445, (2009).

31. J. D. Morris, S. S. Daood, S. Chilton, W. Nimmo. Fuel, 230, 452-473, (2018).

32. J. Lehmann, J. P. da Silva, C. Steiner,T. Nehls, W. Zech, \&, B. Glaser, Plant Soil, 249(2), 343-357, (2003). 